\title{
Moral Understanding, Testimony, and Moral Exemplarity
}

\section{Michel Croce ${ }^{1,2}$ (iD}

Accepted: 27 November 2019/Published online: 9 December 2019

(C) The Author(s) 2019

\begin{abstract}
While possessing moral understanding is agreed to be a core epistemic and moral value, it remains a matter of dispute whether it can be acquired via testimony and whether it involves an ability to engage in moral reasoning. This paper addresses both issues with the aim of contributing to the current debates on moral understanding in moral epistemology and virtue ethics. It is argued that moral epistemologists should stop appealing to the argument from the transmissibility of moral understanding to make a case for their favorite view of moral understanding. It is also argued that proponents of exemplarist moral theories cannot remain neutral on whether the ability to engage in moral reasoning is a necessary component of moral understanding.
\end{abstract}

Keywords Moral understanding $\cdot$ Moral testimony $\cdot$ Virtue $\cdot$ Moral exemplars $\cdot$ Moral epistemology

\section{Moral Understanding: Two Questions}

A central discussion in moral epistemology concerns the epistemic standing that suffices for an individual's action to qualify as morally worthy and for the agent themselves to count as morally virtuous. Generally speaking, many agree that one's actions are incompatible with moral virtue if the agent acts as they do out of moral deference, that is, if they come to believe that $\mathrm{X}$ is right or wrong - and act accordingly — by virtue of blind trust in someone else. For one thing, the pervasiveness of moral disagreement makes it unclear whether we can legitimately talk about authority in the moral domain and assume we might be rational in deferring to others on moral matters. For another, even if moral authorities existed and it were rational for us to trust them on some occasions, it seems clear that something more than the ability to

Michel Croce

mich.croce@gmail.com

1 Department of Philosophy, University of Edinburgh, Dugald Stewart Building, 3 Charles Street, Edinburgh EH8 9AD, UK

2 LanCog, Centro de Filosofia, University of Lisbon, Alameda da Universidade, Lisbon 1649-004, Portugal 
choose an advisor is required for us to aspire to moral virtue. We typically expect from morally virtuous agents not only that they do the right thing in the right circumstances, but also that they do so for the right reasons.

The notion of moral understanding is often seen to be a crucial requirement for one's actions to be compatible with moral virtue. ${ }^{1}$ Yet moral epistemologists disagree about how we should conceive of the notion of moral understanding. In this paper, I shall focus on two specific controversies about the nature of moral understanding, namely (i) whether it is possible to acquire moral understanding via testimony, and (ii) whether it involves an ability to engage in moral reasoning.

As regards (i), reductionists hold that moral understanding boils down to possessing a sufficient amount of moral knowledge and take the fact that moral understanding can be conveyed via testimony as an important virtue of their view. In contrast, non-reductionists have it that possessing moral understanding requires that the subject grasps the relationship between relevant pieces of information about the matter at hand-where the notion of 'grasping', as will become clear, identifies an epistemic standing that is not necessary for a subject to possess moral knowledge. On a non-reductionist perspective, the fact that testimony can convey moral knowledge but not moral understanding is taken as evidence that the latter is irreducible to the former.

The issue with (ii) is independent of the reductionism vs. non-reductionism division in respect of (i) (Sliwa 2017: 525). Rather, it intertwines with another fundamental debate in moral philosophy concerning whether the ability to account for one's understanding is a necessary feature of morally virtuous individuals. Intellectualists maintain that moral virtue requires the possession of this capacity, while anti-intellectualists hold that one can be morally virtuous without being able to give an account of why they act as they do.

This paper purports to advance both debates at once. As for (i), after briefly reconstructing the debate between reductionists and non-reductionists about moral understanding and its transmissibility via testimony ( $(2)$, I shall propose an account of moral understanding that meets the dispositional requirements typical of non-reductionism and that nonetheless can be conveyed via testimony, as reductionists predict (§3). My argument will support a surprising conclusion, namely that neither view can appeal to the argument from moral testimony to claim a positional advantage over its rival. As for (ii), my main goal is to shed light on the need for further inquiry into the connections between moral epistemology and virtue ethics. In particular, section 4 explores some implications of the intellectualism vs. anti-intellectualism divide for Linda Zagzebski's exemplarist moral theory (2017). I will argue that, given the nature of the dispute, Zagzebski cannot remain neutral on whether morally virtuous individuals need to possess the ability to engage in moral reasoning. I will also attempt to motivate the surprising conclusion that, though her view is grounded in neo-Aristotelian virtue ethics, it sits better with anti-intellectualism than with intellectualism when it comes to moral virtue.

\section{Understanding-why, Knowing-why, and their Transmission}

A good way to approach the divide between reductionists and non-reductionists about moral understanding is to begin by establishing a few things on which they seem to agree.

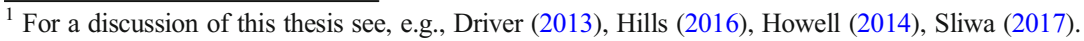


First, both camps conceive of moral understanding as a species of understanding-why relative to moral propositions. In general, understanding-why has to do with local or nonholistic objects, such as propositions, local events, and the like (e.g., understanding why this pizza is too crusty), and involves some degree of engagement with the reasons why something is the case (e.g., with some considerations about the flour that has been used, the temperature of the wood-oven in which it has been baked, or the baking time). ${ }^{2}$ If we apply these considerations to the moral domain, we can think of moral understanding as understanding why $\mathrm{p}$, where $\mathrm{p}$ is a moral proposition such as "Plagiarism is wrong", "You should apologize to your brother", or "Denis Mukwege and Nadia Murad are good people".

Second, it is standard to consider the notion of moral understanding as factive, namely one according to which, for example, I understand why plagiarism is wrong if and only if plagiarism is in fact wrong, or you understand why you should apologize to your brother if and only if there is some fact of the matter which requires that you ask for your brother's forgiveness. ${ }^{3}$

Finally, reductionists and non-reductionists seem to agree that possessing moral understanding is a necessary condition for one to be a good moral advisor in some domain (Annas 2011: 20, 30, 41; Hills 2009: 126; Sliwa 2017: 550-ss), although some controversy remains over whether moral understanding is the appropriate mental state one is required to hold toward the reasons for one's action, in order for such action to be morally worthy (Markovits 2010).

Before getting into the reasons behind the dispute between proponents of the two views, it will be helpful to recall a distinction offered by Sliwa between possessing the capacity of moral understanding and having acquired an instance of moral understanding (2017: 523-ss). As we will see in $\S 4$, the former is key to addressing the question of the links between moral understanding and moral virtue. In contrast, the debate between reductionists and nonreductionists has to do with what is required for an individual to be credited with instances of moral understanding. It is the latter meaning of the term that I am concerned with in the next couple of sections.

The main point of disagreement between reductionists and non-reductionists concerns whether moral understanding, intended as understanding-why $\mathrm{p}$ - where $\mathrm{p}$ amounts to a moral proposition-reduces to knowing-why p. For the sake of simplicity, I shall focus on two (paradigmatic) versions of the theories of moral understanding, namely Hills' non-reductionist view and Sliwa's reductionist approach.

Consider the following propositions: "plagiarism is wrong" (p) because "it is a form of stealing" (q). According to Hills, whether a subject S understands (or knows) why p depends on the epistemic stance $\mathrm{S}$ entertains towards q, that is, with the reasons why p. Knowing why plagiarism is wrong merely requires that $\mathrm{S}$ knows that plagiarizing amounts to stealing and that this is the reason why it is wrong. Understanding why plagiarism is wrong, instead, requires that $\mathrm{S}$ grasps the reasons why this is the case, where grasping involves a broad range of abilities S needs to deploy. In particular, according to Hills, understanding why p entails that, in the appropriate circumstances, S can successfully (2009: 102-103):

\footnotetext{
${ }^{2}$ Detailed considerations on the various kinds of understanding can be found in, e.g., Carter and Gordon (2014), Grimm (2014), Kvanvig (2009), and Pritchard (2009).

${ }^{3}$ As regards factivity, discussion in moral epistemology walks partly away from the parallel debate in epistemology, where it is controversial whether understanding-why should be considered as a factive notion. Factive accounts of understanding-why have been offered in, e.g., Kvanvig (2003) and Pritchard (2009). For non-factive accounts of understanding-why, see, e.g., Elgin (2007) and Zagzebski (2001).
} 
- Follow an explanation of why p given by someone else;

- Explain why p in S's own words;

- Draw the conclusion that $\mathrm{p}$ (or that probably $\mathrm{p}$ ) from the information that $\mathrm{q}$;

- Draw the conclusion that p' (or that probably p') from the information that q' (where p' and q' are similar to but not identical to $\mathrm{p}$ and $\mathrm{q}$ );

- Given the information that $\mathrm{p}$, give the right explanation, $\mathrm{q}$;

- Given the information that p', give the right explanation, q'.

This list individuates necessary and (likely) sufficient abilities for $\mathrm{S}$ to possess moral understanding, that is, to have what Hills calls cognitive control over p (2016: 663). ${ }^{4}$ The fact that cognitive control is composed of abilities, that is, dispositional elements coming in degrees, explains why moral understanding is a gradable notion. This idea is quite intuitive, if we just think that one can be more or less able to explain things in one's own words, more or less able to draw appropriate conclusions from given information, etc.

One of the arguments Hills advances to support a non-reductionist view of moral understanding is that, in general, knowledge-why is not sufficient for understanding-why; thus, $a$ fortiori, moral knowledge(-why) is not sufficient for moral understanding(-why). To prove this, it is enough to show that one can easily possess knowledge-why $\mathrm{p}$ without having cognitive control over p. Moral testimony seems to offer the kind of evidence that nonreductionists are seeking.

Imagine a case in which Emily, a well-published scholar in ethics, tells her friend and freshman Peter that "plagiarism is wrong because it is a form of stealing." Peter can easily acquire moral knowledge via testimony: he comes to believe $\mathrm{p}$ based on reason $\mathrm{q}$ through Emily's words and lacks reasons against her reliability; in fact, he has acquired inductive evidence of her trustworthiness over time. Yet, Hills would argue, unless Peter reflects upon what Emily told him and reaches cognitive control of $\mathrm{p}$ - i.e., that plagiarism amounts to stealing others' intellectual property and passing it off as your own-he fails to possess moral understanding of why plagiarism is wrong. Moral testimony cannot provide Peter with the necessary control because testimony cannot transmit the necessary abilities. Thus, knowledge and understanding require different mental states: knowing requires assenting to the speaker's explanation of why $\mathrm{p}$ is the case, while understanding requires grasping the reasons why $\mathrm{p}$ is the case, that is, the relationship between $\mathrm{p}$ and $\mathrm{q}$ (see Sliwa 2017: 531). In other words, moral understanding requires cognitive work on the part of the agent who acquires it and, unlike knowledge, "does not allow for a substantial division of epistemic labour" (Hills 2016: 671). ${ }^{5}$

Sliwa would give a completely different diagnosis of the plagiarism example. As I have already mentioned, reductionists argue that moral understanding reduces to moral knowledge because understanding-why $\mathrm{p}$ simply requires that one possesses a sufficient amount of knowledge-why $\mathrm{p}$, which, like any form of knowledge, can be acquired via perception and inference but also via testimony. Thus, Sliwa's explanation for why Peter lacks moral understanding in the case above would not appeal to an asymmetry between knowledge and understanding as mental states. Peter and Emily are in the same mental state; rather, they differ

\footnotetext{
${ }^{4}$ See Callahan (2018) for an alternative formulation that is compatible with non-reductionist demands.

${ }^{5}$ Hills also argues against the thesis that knowing-why is necessary for understanding-why by appealing to a widely shared idea that understanding, unlike knowledge, is immune to certain forms of epistemic luck (e.g., Kvanvig 2003; Pritchard 2009; Zagzebski 2001). For the purposes of this paper, we can leave this argument aside. Independent arguments against the transmissibility of moral understanding via testimony can be found in, e.g., Callahan (2018), Enoch (2014), Fletcher (2016).
} 
in respect of how much they know about plagiarism. While Peter merely knows what his friend has told him, Emily is able to "discriminate among various ways the world might be and to correctly locate the actual world on the right side of the divide" (Sliwa 2017: 534). The asymmetry, then, has to do with the epistemic possibilities that Emily, unlike Peter, can discriminate: arguably, both can reject the idea that plagiarism is wrong because it harms one's physical well-being or it goes against gender equality, but only Emily has, say, a welldeveloped concept of intellectual property, how stealing applies to others' ideas or words, and the difference between plagiarizing and infringing copyright.

On Sliwa's account, the fact that Peter and Emily can individuate which epistemic possibility concerning the wrongness of plagiarism obtains explains why both possess moral knowledge. But since Emily, unlike Peter, can recognize a wider number of unrealized epistemic possibilities and account for why they do not obtain, she has acquired an instance of moral understanding while he lacks it. Moreover, the amount of knowledge one possesses about the epistemic possibilities explaining why $\mathrm{p}$ determines how much one understands of $\mathrm{p}$. Thus, reductionism does not eliminate the intuitive difference between understanding as a gradable notion and knowledge as an 'all or nothing' notion (538).

Reducing moral understanding to moral knowledge allows Sliwa to show that moral understanding can be conveyed via testimony. All it takes for a speaker to distribute understanding why $\mathrm{p}$ is that they provide the hearer with enough knowledge of the epistemic possibilities p involves or excludes. Insofar as Emily appropriately describes the wide realm of reasons which might be invoked to justify the wrongness of plagiarism and specifies which one in fact provides justification for $\mathrm{p}$, Peter could acquire moral understanding via her testimony.

Overall, the transmissibility of understanding via testimony on a particular occasion depends on the issue at stake and on the epistemic competence of the subjects involved. In some cases, a single, sufficiently comprehensive testimony can do all the work required for the hearer to acquire understanding. In more complex cases - e.g., those involving matters for which a specific expertise is required - transmitting understanding via testimony plausibly demands that the hearer collect a series of pieces of testimony over time. For it might be a while before they come to be in such a position that their body of knowledge includes or excludes all the relevant epistemic possibilities concerning why $\mathrm{p}$.

Having summarized the central claims of the two main views on the market and having reconstructed the role that moral testimony plays within each theory, we can now show why both reductionists and non-reductionists are wrong about it.

\section{Testifying Moral Understanding: A Third Way}

The goal of this section is to offer an alternative story of how testimony can pass on instances of moral understanding. On the account I propose, moral understanding includes a grasping component, as non-reductionists require, and yet nonetheless it can be conveyed via testimony, as reductionists predict. Thus, the proposed account seeks to demonstrate that neither view can appeal to the argument from moral testimony to claim a positional advantage over its rival. If I am right, reductionists will lose the advantage of being the only ones who can account for the transmission of moral understanding via testimony. In contrast, non-reductionists will have to concede that testimony can convey instances of moral understanding and therefore stop using the argument from the 
transmissibility via testimony as evidence of an asymmetry between knowledge and understanding. 6

This result should not discourage those who are interested in the debate about moral understanding, nor should it prompt them to conclude that neither standard view has the resources to offer a compelling analysis of moral understanding. Quite to the contrary, the proposed account aspires to settle a longstanding controversy in moral epistemology in a way that obligates reductionists and non-reductionists to stop wrangling over moral testimony and propose different arguments in support of their positions.

The section is structured as follows. In $\S 3.1$, I introduce two problems for Sliwa's reductionist take on the transmissibility of moral understanding via testimony. In $\S 3.2$, I outline my alternative view of distributing moral understanding via testimony and show how it solves the problems raised against reductionism. Finally, in §3.3 I defend the proposed view from a typical worry with the fact that recipients of testimony lack epistemic credit for what they achieve.

\subsection{Two Problems with Reductionism: Gradability and Knowing-why}

The main issue with reductionist accounts of how testimony transmits moral understanding is how to make sense of the idea that passing along some amount of knowledge-why provides the hearer with understanding. Specifically, the reductionist proposal has problems with both the quantitative and the qualitative aspects of moral understanding.

The main problem with the quantitative dimension is that it is hard to set a minimum amount of knowledge-why that should suffice for one to achieve moral understanding from another's testimony. A plausible reductionist answer would appeal to the realized and unrealized epistemic possibilities that a subject can properly relate to a given proposition $\mathrm{p}$, but it would have to require more than simply recognizing which epistemic possibility is instantiated in the actual world. Returning to the plagiarism example, it cannot be the case that knowing that plagiarism is a form of stealing is enough for Peter to understand why plagiarism is wrong. If reductionists were to make such a claim, Emily's original testimony would suffice to provide him with moral understanding despite the fact that he does not entertain any other epistemic possibility for why plagiarism is wrong. Thus, there would be no need for an account of understanding-why to impose that one has to be able to discriminate which epistemic possibilities are not realized.

In contrast, non-reductionists appear to be in a position to avoid the problem with the minimum requirements for something to be an instance of understanding. For the grasping component of moral understanding imposes a qualitative - rather than quantitative - difference between knowing-why and understanding-why. Several definitions of the notion of grasping have been given in the recent literature about understanding. What they all have in common is the idea that to grasp something involves perceiving connections between different but related elements, 'seeing' their relationship, where this might even involve 'aha' or 'eureka' experiences. ${ }^{7}$ For the purposes of this paper, then, suffice it to say that non-reductionists avoid the problem with the quantitative dimension of understanding by assuming that knowledge and understanding are two separate and somewhat independent epistemic states. Hence, no amount of knowledge-why will in itself allow one to acquire understanding-why.

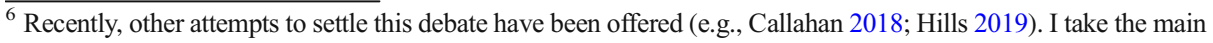
virtue of my attempt to be the fact that it purports to solve the dispute without invoking any revision of the traditional views or of the standard notion of moral understanding.

${ }^{7}$ For more on the relation between understanding and 'aha' experiences, see, e.g., Grimm (2012), Kvanvig (2011). For a thoughtful discussion about understanding and the virtue of insightfulness, see Carter (2017).
} 
Let us assume that reductionists can fix this problem by setting some kind of threshold of knowing-why above which one counts as possessing moral understanding. The other problem has to do with the qualitative dimension of moral understanding, that is, with the very idea that by receiving via testimony enough information about the epistemic possibilities for why $p$ is the case, a hearer can acquire moral understanding. Imagine a revised version of the plagiarism example, in which Emily not only tells Peter that plagiarism is wrong (p) because it is a form of stealing (q), but she also mentions all the different reasons that could be adduced to justify the immorality of plagiarizing and explains why it can be taken as a form of theft although nothing is materially stolen. We can again suppose that Peter acquires a great deal of moral knowledge via Emily's testimony. However, this scenario is perfectly compatible with the fact that he lacks any idea of how these reasons explain — or fail to explain — why p.

For it is enough for Peter to acquire testimonial knowledge that he makes minimal sense of the content of Emily's testimony and has evidence in favor of her reliability. This does not necessarily involve having the resources to acknowledging the conceptual relationship between stealing and plagiarizing. Similarly, a patient can know why acid reflux can increase asthma symptoms via their doctor's explanation despite the fact that they do not understand the doctor's explanation of the complex mechanisms that regulate the interaction between digestion and asthma. Thus, to the extent that Peter fails to recognize the connection between stealing and plagiarizing, the reason why passing off another's words as your own constitutes an intellectual property theft, how plagiarism differs from copyright infringement, and so on and so forth, he will still lack moral understanding - similarly, the patient who fails to recognize how reflux affects asthma will lack understanding of why this is the case.

This example shows that it takes more for one to understand why $\mathrm{p}$ than to acquire testimonial knowledge of the relationship between $\mathrm{p}$ and $\mathrm{q}$, even when the speaker does their best to make that connection clear to the hearer. Thus, reductionists appear to have a problem not only with establishing the amount of knowledge-why required for a hearer to acquire testimonial understanding, but also - and more importantly — with the very idea that a sufficient amount of knowledgewhy may in principle provide the hearer with moral understanding.

It is important to bear in mind that this argument against the reductionist account of testifying moral understanding does not in itself speak in favor of non-reductionism. In order for non-reductionists to have a point, they ought to show that moral understanding cannot be acquired through testimony. It is against this latter claim that I shall argue in the next section.

\subsection{An Alternative Account of the Transmissibility of Moral Understanding}

The argument I want to offer against the alleged impossibility of transmitting moral understanding via testimony amounts to showing that there can be cases in which testimony conveys moral understanding, where this involves the possession of cognitive control on the part of the hearer. The proposed argument relies on a helpful distinction Kenneth Boyd has recently drawn between two components of understanding, namely an informational component and a grasping component (2017). ${ }^{8}$ According to Boyd, the informational component amounts to possessing the information necessary to acquire understanding, while the grasping component

\footnotetext{
${ }^{8}$ It should be noted that Boyd (2019) has proposed an alternative and independent strategy to overcome the problem of the transmissibility of moral understanding, namely one that appeals to testimony as a cooperative source. I shall set this proposal aside, as I am convinced that the problem under consideration can be successfully addressed without resorting to his most recent conceptual framework.
} 
involves both the apt exercise of some kind of cognitive abilities on the part of the hearer and the "relationships between the thing understood and either the reasons that make that thing true or propositions that are related to it" (114).

Since testimony does not convey epistemic abilities from the speaker to the hearer, one cannot acquire the grasping component through testimony and therefore testimony cannot transmit understanding-why, as non-reductionists would predict. However, this is only the natural result in a specific range of cases that Boyd calls instances of difficult understanding, that is, cases requiring long-term effort and the exercise of many abilities on the part of the hearer, such as understanding why Fermat's Last Theorem can be solved or why time, unlike space, seems to flow only in one direction. Other kinds of understanding, namely easy understanding and easys understanding, impose less demanding requirements. As for the former, anyone possessing minimum conceptual resources can achieve easy understanding simply "by making sense of" the speaker's utterances (119). For example, almost everyone can achieve understanding of why "I need to leave Rome today" (p) by making sense of my further testimony that "I am supposed to attend a dear friend's wedding tomorrow in London" (q). As for the latter, easy $\mathrm{s}_{\mathrm{s}}$ understanding follows a transmission mechanism similar to the one concerning easy understanding, but it only applies to individuals who have a specific background familiarity with complex issues and have developed the necessary abilities to grasp the information received without undertaking further reflective processes. For example, a philosophy student might easily understand why "knowledge is factive" (p) through a further explanation that "knowledge is an attitude that one can have only to true propositions" (q), yet testimony fails to transmit understanding to individuals without a background in philosophy.

How can it be, though, that testimony itself provides someone with understanding in those easy or easy $\mathrm{s}_{\mathrm{s}}$ situations if grasping does not transmit? Satisfying the grasping component in these cases does not demand much effort on the hearer's part: making sense of the testimony is all it takes for them to grasp the relationship between $\mathrm{p}$ and $\mathrm{q}$. Hence, although the grasping component, technically speaking, does not transmit from one person to another, it is still true that the mere fact that one transmits their understanding-why through testimony suffices to let the hearer acquire understanding-why. For making sense of the speaker's utterances allows the hearer to achieve both components of understanding at once. The argument thus demonstrates that easy understanding and easy $_{\mathrm{s}}$ understanding can be passed on via testimony, just like knowledge. 9

These considerations on different kinds of understanding easily apply to the moral domain too. Going back to the original version of the plagiarism example, establishing whether Peter can acquire moral understanding of why plagiarism is wrong from Emily's testimony depends on his background familiarity with ethical issues and intellectual abilities. If Peter already

\footnotetext{
${ }^{9}$ Someone might object that, on a standard view of what transmission is, for (moral) understanding to be transmitted a subject B should understand 'why p' merely as a result of a subject A's testimony 'why p'. The account defended here might seem to deviate from a standard account of transmission, in that for understanding to be transmitted it is also required that B exercises their abilities to make sense of A's testimony. As a response, notice that transmission requires minimal work on the part of $\mathrm{B}$ even when the exchange transfers knowledge rather than understanding. The sole difference is that transmitting understanding requires that $\mathrm{B}$ grasps/has cognitive control over the connection between $\mathrm{p}$ and $\mathrm{q}(=$ the reason(s) why $\mathrm{p})$, whereas transmitting knowledge merely imposes that $B$ makes minimal sense of the content of $p$ and of the fact that $q$ is the reason why $p$, as required by assenting (see §2). Thus, the mere fact that $\mathrm{B}$ has to exercise their abilities to acquire understanding via A's testimony does not support the conclusion that the proposed account endorses a non-standard view of transmission. I thank an anonymous reviewer for urging this clarification.
} 
possesses (a) enough background information about stealing and passing off another's words as your own, and (b) the necessary abilities to link the two concepts, nothing seems to prevent Emily's testimony from transmitting an instance of moral understanding to him. For while Emily takes care of passing on the informational component, (a) and (b) allow him to satisfy the grasping component simply by making sense of her words, as in cases of easy $\mathrm{s}_{\mathrm{s}}$ understanding. In contrast, were Peter to lack the conceptual resources to grasp how stealing may involve intellectual property, Emily's testimony could at best convey moral knowledge, yet not moral understanding. The same argument applies to the revised version of this example: the main difference between these cases would just be that in the latter Peter is required to possess (b), while a significant portion of the work necessary to fulfil (a) is done by Emily's detailed testimony.

Before addressing a relevant objection against this argument, let me briefly shed light on its advantages, namely how it avoids the problems with reductionism introduced in §3.2. As regards the quantitative dimension of moral understanding, my view can concede that moral understanding comes in degrees, yet the grasping component warrants a qualitative difference between moral knowledge and moral understanding. That is: Peter could acquire more or less understanding from Emily depending on the comprehensiveness of her testimony, the breadth and depth of his background familiarity with ethical issues, and the degree to which he has developed relevant intellectual virtues. However, he acquires an instance of moral understanding only insofar as he grasps why stealing intellectual property is morally wrong.

As regards the qualitative dimension of moral understanding, all the information about the epistemic possibilities that, on Sliwa's account, are to be entertained or excluded for why $p$ is the case aptly features in the informational component of understanding on my account, but in no way helps one satisfy the grasping component. Thus, the distinction between the two components of understanding shows that providing Peter with more information about the various reasons why plagiarism could be right or wrong does not guarantee that he fulfills the grasping component and therefore that he acquires moral understanding via Emily's testimony.

Hence, the proposed view of moral understanding is in a position to account for the transmissibility of (instances of) understanding-why without reducing this notion to a mere sum of (instances of) knowing-why.

\subsection{Moral Understanding and the Problem of Epistemic Credit}

A major worry with any account of the transmissibility of moral understanding has to do with the problem of epistemic credit. Acquiring an instance of (moral) understanding, in general, requires epistemic work on the part of the subject who needs to deploy their intellectual abilities. Yet in the case of the transmission of moral understanding via testimony, a critic would argue, the hearer is not doing enough work for their cognitive success to be credited to them.

The objection closely resembles one that has been famously raised by Jennifer Lackey against credit and virtue-theoretic epistemologies, that is, those theories on which a subject has knowledge to the extent that the true belief they have formed can be appropriately credited to them - or is the product of their cognitive abilities. In paradigmatic instances of testimonial knowledge - e.g., the case of someone acquiring knowledge about the location of the train station in an unknown town from a random passerby - the hearer forms their belief by relying upon the speaker's words, that is, by trusting them. Thus, since most part of the epistemic work that allows the hearer to form a true belief is done by the speaker, Lackey notes, credit theories 
and virtue epistemology would be committed to the unreasonable conclusion that the hearer does not acquire knowledge from testimony (2007).

The problem of the epistemic credit should be more troubling in the case of understanding, if we bear in mind, first, that achieving understanding in general involves a greater deal of intellectual abilities than achieving knowledge does, and second, that testimony does not seem a suitable way to pass on intellectual abilities.

Nonetheless, the answers that have been put forth to address the problem in the case of knowledge provide us with a strategy for replying to the objection in the case of understanding too, or so I shall argue. Specifically, the answer I shall offer combines important remarks from Riggs (2009) and Pritchard (2010, 2012). Riggs highlights that whenever we receive a piece of testimony, we should at least be counterfactually sensitive to clues of hesitancy, mendacity, or unreliability, no matter whether our testimonial belief will result from direct transmission or an inferential process (2009: 211). Thus, regardless of which theory of testimonial justification one wants to endorse, the hearer has some work to do even in ordinary cases of testimonial knowledge. Pritchard, instead, draws an important distinction between cognitive successes that are primarily creditable to the epistemic subject and cognitive successes that are creditable to the subject to a significant degree (2010: 55; 2012: 273). Paradigmatic cases of transmission of testimonial knowledge might not feature in the former set of cognitive successes, but they do feature in the latter precisely because the hearer's sensitivity to the aforementioned counterfactual elements is key to account for her cognitive achievement, i.e., the fact that she acquires knowledge via testimony.

If we apply these considerations to the proposed account of moral understanding, it should not be difficult to see that the problem of easy credit can be successfully explained away. For one thing, the very fact that understanding requires the satisfaction of a grasping component accommodates the idea that the hearer needs to do some epistemic work. In general, it is reasonable to expect that understanding demands more effort on the part of the hearer than that needed to satisfy the counterfactual sensitivity requirement in the case of knowledge. However, we have just seen that in cases of easy and easy $y_{s}$ understanding, the hearer is able to activate and successfully complete grasping processes simply by making sense of the speaker's words. It is not necessary to dwell on whether such grasping processes require more or less effort than the counterfactual sensitivity does: it might well be the case that acquiring testimonial knowledge about some extremely complex matters requires more work on the part of the hearer than acquiring understanding in easy situations. ${ }^{10}$ All that matters here is to show that even the easiest cases of transmission of understanding require some cognitive effort on the part of the hearer.

For another thing, though easy cases of transmission of understanding do not constitute cognitive successes that are primarily creditable to the hearer-since a lot hinges on whether the speaker's testimony is clear and comprehensive enough for the hearer to acquire understanding - they are still cognitive successes that are creditable to the hearer to a significant degree. For the hearer would not acquire any moral understanding unless they were in a position to grasp the connection between the moral proposition at stake and the reasons adduced in support of that proposition. Thus, we can conclude that the distinction between the two components of understanding and a careful consideration of the role played by the grasping component allow the proposed account of moral understanding to successfully address the concern with epistemic credit.

${ }^{10}$ See Malfatti (forthcoming) for extensive discussion of this point. 
The proposed argument should not lead us to overlook the role the speaker plays in cases of transmission of easy and easy $y_{\mathrm{s}}$ understanding. ${ }^{11}$ The speaker's epistemic credit in testifying understanding relates to two aspects: one has to do with the informational component and amounts to transmitting true and justified propositions; the other has to do with the grasping component and amounts to tailoring the breadth and depth of their testimony in such a way that the hearer can grasp their meaning without further effort. If we go back to the plagiarism example, it should not be taken for granted that Emily's mere uttering p and q suffices to transmit moral understanding about the wrongness of plagiarizing to an interlocutor. It might be enough for Peter to grasp why plagiarism is wrong, supposing that he is already familiar with the concepts of plagiarizing, stealing, and intellectual property, yet not for a younger child who lacks these concepts. In this latter situation, whether moral understanding can be passed on via testimony depends both on the child's conceptual background and on Emily's ability to provide them with an explanation that fits their intellectual resources. ${ }^{12}$

As demonstrated by many examples involving education, both the speaker and the hearer have some work to do to ensure the transmission of epistemic goods. The degree to which each individual is involved admits of some variation depending on the nature of the epistemic good at stake - that is, whether it is knowledge or understanding that is distributed - but we should not expect to discover any epistemically significant asymmetry in the transmission processes involving knowledge and easy or easy $\mathrm{s}_{\mathrm{s}}$ instances of understanding.

To summarize: this section has been devoted to showing that both reductionists and nonreductionists are wrong about moral understanding and moral testimony. In §3.1, I showed that, pace reductionists, passing on knowing-why via testimony does not suffice to provide one with moral understanding. In $\$ 3.2$, I outlined my alternative account of understanding-why based on the distinction between an informational component and a grasping component and showed how, on this account, pace non-reductionists, understanding can be transmitted via testimony. $\$ 3.3$ explained away the problem with the idea that the hearer does not deserve credit for any moral understanding they acquire via testimony.

\section{Moral Exemplars and the Capacity of Moral Understanding}

The upshot of section 3 was to settle a longstanding debate in moral epistemology concerning the relationship between (instances of) moral understanding and (instances of) moral testimony. Moral understanding intended as a capacity incurs problems of its own. In this section, I shall explore whether the capacity of moral understanding requires the ability to engage in moral reasoning. Rather than arguing in favor of an intellectualist or an anti-intellectualist approach, the section shows that this debate has an impact on the discussion about the requirements for moral virtue and moral exemplarity. I will focus on Zagzebski's exemplarist moral theory, as she contends that her view need not take a stand on whether the aforementioned ability is necessary for becoming an exemplar. Against this claim, I shall argue that the accounts of moral exemplars resulting from how the two rival views answer such question are so different that Zagzebski cannot remain neutral on the issue.

As should be clear from the characterization of cognitive control, Hills holds that the capacity of moral understanding requires both the ability to follow explanations given by

\footnotetext{
${ }^{11}$ See Gordon (2017: §4) for considerations on the speaker's role in transmitting understanding.

${ }^{12}$ See Croce (2018) for further considerations on transmitting understanding to children and novices.
} 
someone else - i.e., condition (i) of her notion of cognitive control - and the ability to give explanations, that is, to explain why $\mathrm{p}$ in one's own words-i.e., condition (ii). Sliwa has recently challenged this view by arguing that Hills unjustifiedly conflates possessing moral understanding and possessing the ability to articulate it. Sliwa proposes the following example:

Consider Julie, who is, by all accounts, a morally good person: honest, caring, and kind. She is also extremely morally competent; for any moral situation she finds herself in, she does the right thing because it strikes her as the right thing to do, and it strikes her as the right thing to do because she responds to the morally relevant features of the situation. [However,] when pressed for an explanation, she might just shrug her shoulders and offer: "it's just the right thing to do." Or perhaps: "it would be unkind not to help." (2017: 541).

This example, Sliwa argues, puts pressure on Hills because we should find it intuitive that Julie has deep moral understanding despite the fact that she lacks the ability to give appropriate explanations of her moral judgments. On Sliwa's view, distinguishing between the capacity of moral understanding and the ability to articulate it explains why some morally relevant situations strike us as inherently right or wrong although we might well lack the right words to justify our judgments.

One way in which Hills could resist this conclusion and stick to the idea that Julie lacks the capacity of moral understanding is to argue that we want our moral advisors to be people who possess this capacity - that is, something for which the ability to give proper explanation of one's moral judgments is required. On closer inspection, this argumentative line does not seem promising because, as Sliwa points out, it can be the case that one has the capacity of moral understanding and serves as a moral advisor without being able to articulate their understanding properly (542). Moral exemplars are the paradigmatic example of moral advisors who offer guidance through their behavior rather than — or, at least, more than — their testimony. To the extent that Julie's behavior helps her acquaintances figure out what to believe or how to act in a morally salient situation, she is providing moral advice in the way moral exemplars do.

Sliwa's argument against conflating moral understanding with the ability to give explanations of moral propositions seems compelling. As a matter of fact, it can well be the case that one has the former without the latter, as Julie does in the aforementioned example. The opposite also seems true, if we imagine that some individuals may have developed sophisticated skills in communicating complex concepts to others, especially laypeople, and yet fail to see the connection between $\mathrm{p}$ and $\mathrm{q}$ when this involves some sphere of interest or clashes with their deeply entrenched prejudices. ${ }^{13}$

Nonetheless, Sliwa's argument has a wider impact on the debate about moral virtue and moral exemplarism than she herself has argued. For her argument entails that the ability to provide moral explanations is not necessary for one to be a moral exemplar. If we stick to Zagzebski's seminal work on this topic, moral exemplars are exceptionally good individuals whose behavior we admire and desire to imitate. The most appropriate way to cash out their exceptional goodness is in terms of moral virtues, ${ }^{14}$ which Zagzebski defines as deep and enduring acquired traits that we admire upon reflection, consisting of a disposition to have a

\footnotetext{
${ }^{13}$ Sliwa makes the case of moral philosophers who can reason well about fairness and equality but systematically fail to spot instances of gender inequality right in front of them (2017: 543).

${ }^{14}$ See, e.g., Adams (1984), Wolf (1982).
} 
certain emotion that initiates and directs action towards an end, and reliable success in reaching that end (2017: 113).

The central question linking moral exemplarity and the ability to provide moral explanations is whether being morally virtuous requires that one possesses this ability. Sliwa's view aligns with anti-intellectualism - also called the naivety view (Hills 2015: 11) - according to which it is not characteristic of a fully morally virtuous person that they have the aforementioned explanatory ability. All that matters for full moral virtue, from an anti-intellectualist perspective, is that one be reliably disposed to do the right thing for the right reasons, regardless of whether one can also explain why they act as they do. In contrast, Hills answers this question in the affirmative following the intellectualist take typical of Aristotelian virtue ethics (Annas 2011; Hursthouse 1999), according to which a fully morally virtuous person not only grasps the morally relevant features of a situation in which they find themselves, but also has the ability to explain why a course of action is right (or wrong).

Zagzebski holds that that "exemplarism has the advantage of neutrality on the relative place of reasoning and emotion in moral behavior" (2017: 142) and takes this to be a further advantage of her view, one that presumably allows her to avoid entering into the dispute between intellectualists and anti-intellectualists. In principle, this move seems entirely legitimate, as Zagzebski might well think that the ability to give an explanation of one's actions is a separate condition on moral exemplarity, namely one that is compatible with—but not entailed by—possessing moral virtue. ${ }^{15}$ However, she also points out that Annas' account of moral virtue fits well with her own exemplarist model of moral learning (2017: 138, n. 12), thereby eliciting the thought that moral exemplarism should align with the intellectualist tradition.

This ambiguity calls for further investigation especially because intellectualism and antiintellectualism deliver two extensionally different sets of moral exemplars depending on whether the ability to give an account of one's action is taken to be necessary for moral virtue. In the remainder of this section, I shall explore whether Zagzebski's account of moral exemplars is compatible with the diagnosis that intellectualists and anti-intellectualists would offer of Julie's case cited above. The proposed analysis will support a surprising conclusion, namely that exemplarism is bound to fit better with anti-intellectualism than with intellectualism.

According to a strong intellectualist reading, Julie is not a moral exemplar because exemplars are exceptionally virtuous individuals and moral virtue requires the ability to engage in moral reasoning which she lacks by definition. However, it is far from clear that this diagnosis of the case sits well within Zagzebski's theory, for Julie has the right motivations and reliably succeeds in doing the right thing for the right reason. Surely, her admirability does not depend on the ability to give moral explanations; rather, it is her behavior that manifests her exceptional attitude of care, honesty, and kindness. To the extent that other individuals can appreciate her virtues and admire her acts, there seems to be nothing to prevent the exemplarist dynamic from occurring (Croce 2019): Julie's example can naturally lead those who admire her to become more virtuous and might even be used to educate pupils in the spheres of honesty, care, and kindness.

Intellectualists might not be entirely satisfied with this strong reading and propose an alternative, i.e., weaker, diagnosis of the case, according to which Julie is only virtuous

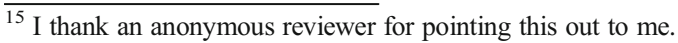


to some degree. For she is genuinely honest, kind, and caring, but fails to be fully morally virtuous, due to the fact that she does not possess all the virtues and lacks a relevant component of moral understanding-i.e., the capacity to engage in moral reasoning. This diagnosis does not reduce the standards of intellectualism as a theory-which is committed to the unity of the virtues thesis (e.g., Annas 2011; Russell 2009; Wolf 2007) as well as to the thesis that moral virtue requires the ability to give an explanation of one's instances of moral understanding - but only those of moral exemplarity. Simply put, on this view "partial moral virtue" (Hills 2015: 34) might be sufficient for one to be a moral exemplar. The proposed weaker intellectualist reading has a relevant drawback of its own. On a standard exemplarist approach, moral exemplars are not less-than-fully virtuous individuals, but rather exceptionally virtuous individuals, namely ones whose virtuousness is most evident in how they behave, thereby eliciting our admiration. Thus, the very idea of an exemplar as a partially virtuous individual does not sit well with the spirit of an exemplarist moral theory.

The limits of the intellectualist diagnoses of Julie's case invite us to consider alternative readings that anti-intellectualists might have to offer. The most plausible is one in which Julie is a moral exemplar in that she displays some virtues at an exceptional level and manages to deploy them in any situation in which she finds herself, as Sliwa describes. In other words, Julie embodies the features of what Driver would consider an expert practitioner of honesty, kindness, and care, that is, someone who is exceptionally virtuous because they do the right thing in the right situation although their moral understanding may not include the ability to give a proper account of their decisions and actions (2013). ${ }^{16}$ This diagnosis has some advantages over the alternatives. Unlike the strong intellectualist reading, it grants Julie the status of a moral exemplar, as we would intuitively do before entering into the discussion between intellectualism and anti-intellectualism. Unlike the weak intellectualist reading, it considers moral exemplarity as an exceptional — rather than a partial — form of moral virtuousness and is not committed to the unity of the virtues thesis. In contrast, anti-intellectualists typically endorse a disunitarist perspective, according to which one can possess a genuine virtue without possessing all others (e.g., Badwhar 1996; Walker 1993; Williams 1985). This view is more concessive than intellectualism insofar as it accommodates the idea that fulfilling the requirements of an expert practitioner of some - and not necessarily all — of the virtues, as Julie does, suffices for one to be a moral exemplar.

The proposed analysis has clarified that morally good individuals-like Julie in our example - may feature in the set of moral exemplars depending on whether one deems the ability to engage in moral reasoning as necessary for moral virtue. This should suffice to explain why Zagzebski is not entitled to stay neutral on the issue and to provide (at least partial) support for the thesis that her exemplarism sits better with anti-intellectualism than intellectualism. Before concluding, I shall offer two further reasons that speak in favor of this conclusion.

The first reason has to do with Zagzebski's proposed methodology to ground her moral theory in morally exemplary subjects instead of concepts such as "human nature" or "reason". Zagzebski is clear that virtues make people admirable (2017: 113) and that they involve knowledge and understanding (1996: 134). If we stick to her exemplarist methodology, though, it seems evident that in most cases our admiration of moral exemplars is in fact

\footnotetext{
${ }^{16}$ Expert practitioners differ from what Driver calls expert judgers in that the former are responsive to moral reasons without being aware of what these reasons are and/or able to spell them out in an explanation, as the latter do reliably (2013: 286).
} 
directed toward the actions revealing their virtuousness rather than the considerations they might offer to explain why they act as they do. Far from providing a conclusive argument in favor of anti-intellectualism, this remark indicates that there seems to be no strong reason why, on an exemplarist approach, the ability to give an account of one's moral reasoning should be a necessary feature of moral exemplars. Rather, what matters is that moral exemplars show us what virtue amounts to in concrete situations.

The second reason has to do with Zagzebski's explicit considerations on the unity of the virtues thesis. She argues that empirical observation of exemplars can offer a way to verify this thesise.g., by showing us whether displaying a vice is sufficient to undermine moral exemplarity - and that she herself does not endorse it (2017: 120-121). Anti-intellectualism appears to be better suited to accommodate Zagzebski's concern precisely because it is compatible with disunitarism about moral virtues and, in turn, can account for the moral exemplarity of individuals like Julie, who display some virtues to an exceptional degree but lack full moral virtue. ${ }^{17}$

This section has explored an important issue with moral understanding intended as a capacity, that is, a particular way in which moral understanding has a bearing on the debate about moral virtue and exemplarity. I first argued that if the capacity of moral understanding is a necessary condition for one to be a moral exemplar, then proponents of exemplarist moral theories are committed to take a stand on whether moral understanding involves an ability to engage in moral reasoning. I then attempted to motivate the idea that anti-intellectualism about moral virtue accommodates the demands of Zagzebski's exemplarism better than intellectualism does.

\section{Conclusion}

It comes as no surprise that questions about the role of moral understanding in our intellectual and practical agency, and the relationship between the capacity of moral understanding and moral virtue are receiving an increasing level of attention in current discussions in moral epistemology and virtue ethics. This work has sought to advance both debates at once by showing what theorists in either area should (not) do. As regards the debate about moral testimony and moral understanding, I argued that neither reductionism nor non-reductionism should appeal to the argument from moral testimony to claim a positional advantage over its rival view. On the account I offered ( $\$ 3)$, the fact that possessing instances of moral understanding involves a dispositional element - i.e., cognitive control—does not exclude that moral understanding can be transmitted via testimony. As regards the debate about the capacity of moral understanding, virtue, and moral exemplarity, I argued that proponents of exemplarist theories need to say more about whether being a virtuous exemplar requires that one has the ability to engage in moral reasoning (§4). Furthermore, I suggested that Zagzebski's exemplarist moral theory aligns better with anti-intellectualist views of moral virtue, according to which the ability to engage in moral reasoning is not a necessary condition for one to be virtuous. If my arguments hit their target, this paper has suggested new directions toward which the discussion about moral understanding in moral epistemology and virtue ethics should proceed. ${ }^{18}$

\footnotetext{
${ }_{17}^{17}$ have defended this claim at length in Croce and Vaccarezza (2017).

18 Thanks to Duncan Pritchard and two anonymous reviewers for their comments on an earlier version of this paper. This paper was presented at the 3rd Aretai Conference, held at the European University (Rome) in 2018, and I am grateful to the audience for their comments. Work on this article has received funding from the Fundação para a Ciência e a Tecnologia (FCT, Portugal) under grant agreement CEECIND/02143/2017.
} 
Open Access This article is licensed under a Creative Commons Attribution 4.0 International License, which permits use, sharing, adaptation, distribution and reproduction in any medium or format, as long as you give appropriate credit to the original author(s) and the source, provide a link to the Creative Commons licence, and indicate if changes were made. The images or other third party material in this article are included in the article's Creative Commons licence, unless indicated otherwise in a credit line to the material. If material is not included in the article's Creative Commons licence and your intended use is not permitted by statutory regulation or exceeds the permitted use, you will need to obtain permission directly from the copyright holder. To view a copy of this licence, visit http://creativecommons.org/licenses/by/4.0/.

\section{References}

Adams RM (1984) Saints. J Philos 81:392-401

Annas J (2011) Intelligent virtue. Oxford University Press, Oxford

Croce M (2018) Expert-oriented abilities vs. Novice-oriented abilities: An alternative account of epistemic authority. Episteme 15:476-498

Croce M (2019) Exemplarism in moral education: Problems with applicability and indoctrination. J Moral Educ 48:291-302

Croce M, Vaccarezza MS (2017) Educating through exemplars: Alternative paths to virtue. Theor Res Educ 15:519.

Badwhar NK (1996) The limited unity of virtue. Nous 30:306-329

Boyd K (2017) Testifying understanding. Episteme 14:103-127

Boyd K (2019) Moral understanding and cooperative testimony. Canadian Phil Quarterly. https://doi.org/10.1017 /can.2019.3

Callahan LF (2018) Moral testimony: a re-conceived understanding explanation. Philos Q 68:437-459

Carter A (2017) Virtuous insightfulness. Episteme 14:539-554

Carter A, Gordon E (2014) Objectual understanding and the value problem. Am Philos Q 51:1-13

Driver J (2013) Moral expertise: judgment, practice, and analysis. Soc Philos Policy 30:280-296

Elgin C (2007) Understanding and the facts. Philos Stud 132:33-42

Enoch D (2014) A defence of moral deference. J Philos 111:1-30

Fletcher G (2016) Moral testimony: once more with feeling. In: Shafer-Landau R (ed) Oxford studies in Metaethics. Oxford University Press, Oxford, pp 45-73

Gordon E (2017) Social epistemology and the acquisition of understanding. In: Grimm S, Baumberger C, Ammon S (eds) Explaining understanding: new perspectives from epistemology and philosophy of science. Routledge, London, pp 293-317

Grimm S (2012) The value of understanding. Philos Compass 7:103-117

Grimm S (2014) Understanding as knowledge of causes. In: Fairweather A (ed) Virtue epistemology naturalized: bridges between virtue epistemology and philosophy of science. Springer, New York, pp 293-317

Hills A (2009) Moral testimony and moral epistemology. Ethics 120:94-127

Hills A (2015) The intellectuals and the virtues. Ethics 126:7-36

Hills A (2016) Understanding why. Nous 50:661-688

Hills A (2019) Moral testimony: transmission versus propagation. Philos Phenomenol Res. https://doi. org/10.1111/phpr.12595

Howell RJ (2014) Google morals, virtue, and the asymmetry of deference. Nous 48:389-415

Hursthouse R (1999) On virtue ethics. Oxford University Press, Oxford

Kvanvig J (2003) The value of knowledge and the pursuit of understanding. Cambridge University Press, New York

Kvanvig J (2009) The value of understanding. In: Haddock A, Millar A, Pritchard D (eds) Epistemic Value. Oxford University Press, Oxford, pp 95-111

Kvanvig J (2011) Millar on the value of knowledge. Aristot Soc Suppl Vol 85:83-99

Lackey J (2007) Why we don't deserve credit for everything we know. Synthese 158:345-361

Malfatti F (Forthcoming) Can Testimony Transmit Understanding? Theoria

Markovits J (2010) Acting for the right reasons. Philos Rev 119:201-242

Pritchard D (2009) Knowledge, understanding, and epistemic value. Roy I Ph S 64:19-43

Pritchard D (2010) Knowledge and understanding. In: Pritchard D, Millar A, Haddock A (eds) The nature and value of knowledge: three investigations. Oxford University Press, Oxford, pp 3-88

Pritchard D (2012) Anti-Luck Virtue Epistemology. J Philos 109:247-279

Riggs W (2009) Two problems of easy credit. Synthese 169:201-216

Russell D (2009) Practical intelligence and the virtues. Oxford University Press, Oxford 
Sliwa P (2017) Moral understanding as knowing right from wrong. Ethics 127:521-552

Walker ADM (1993) The incompatibility of the virtues. Ratio 6:44-60

Williams B (1985) Ethics and the limits of philosophy. Harvard University Press, Cambridge

Wolf S (1982) Moral saints. J Philos 79:419-439

Wolf S (2007) Moral psychology and the Unity of the virtues. Ratio 20:145-167

Zagzebski L (1996) Virtues of the mind: an inquiry into the nature of virtue and the ethical foundations of knowledge. Cambridge University Press, New York

Zagzebski L (2001) Recovering understanding. In: Steup M (ed) Knowledge, truth, and duty: essays on epistemic justification, virtue, and responsibility. Oxford University Press, Oxford, pp 235-252

Zagzebski L (2017) Exemplarist moral theory. Oxford University Press, Oxford

Publisher's Note Springer Nature remains neutral with regard to jurisdictional claims in published maps and institutional affiliations. 